\title{
PENGARUH PENDAPATAN TERHADAP KESEJAHTERAAN ANGGOTA KOPERASI VIYATA VIRAJATI SESKO AD BANDUNG
}

\author{
Rezza Anni Musrofah ${ }^{1}$, Dian Candra Fatihah ${ }^{2}$ \\ Program Studi Administrasi Keuangan, Fakultas Ekonomi dan Bisnis, Politeknik Piksi \\ Ganesha \\ ${ }^{1}$ musrofahrezza96@gmail.com \\ 2diancandrafatihah@gmail.com
}

\begin{abstract}
ABSTRAK
Penelitian bertujuan untuk mengetahui pengaruh pendapatan terhadap kesejahteraan anggota koperasi Viyata Virajati Sesko AD Bandung. Selanjutnya teknik analisa yang dipakai adalah analisis deskriptif, uji validitas, analisis regresi linier sederhana, uji reabilitas, koefisien korelasi, koefisien determinasi, uji normalitas dan uji hipotesis. Dari penelitian yang telah dilakukan, maka hasil koefisien korelasinya adalah 0,666 (66,6\%) memiliki arti yang kuat, selanjutnya untuk hasil koefisien determinasinya adalah $44,4 \%$ (berarti seberapa besar pengaruh pendapatan terhadap kesejahteraan) dan untuk sisanya 55,6\% (berarti pengaruh dari luar). Untuk pengaruh regresi linier sederhana $\mathrm{Y}=\mathrm{a}+\mathrm{bX}=8,055+1,190 \mathrm{X}$, yang berarti untuk setiap kenaikan 1 nilai pendapatan maka kesejahteraan akan meningkat sebesar 1,190. Hasil uji t telah diperoleh ( $\mathrm{t}$ hitung $>\mathrm{t}$ tabel) $(5,132>1,692)$. Kesimpulannya bahwa pengaruh pendapatan terhadap kesejahteraan koperasi memiliki hubungan yang kuat, dilihat dari antusiasnya anggota koperasi membeli barang di toko koperasi dan pendapatan yang diperoleh dari koperasi bisa dinikmati secara langsung oleh anggotanya.
\end{abstract}

Kata kunci: Pendapatan, Kesejahteraan anggota, Koperasi

\section{ABSTRACT}

The study aims to know what income is doing to the welfare of the viyata virajati cooperative members of Bandung AD. Further analysis techniques are descriptive analysis, validity tests, simple linear, regression analysis, reliability tests, correlation coefficiencies, determinations, normality tests, and hypothetical testing. Rese arch has done, so the coefficient results of its correlation are 0.666 have a strong sense, and the determinative coefficiencies, in turn, are $44.4 \%$ (meaning how much income affects prosperity) and the remaining 55.6\% (meaning external influence). For a simple, linear regression influence $Y=a+b X=8.055+1.190 x$, which means for every increase of one income value, welfare will increase by 1.190. T test results have been obtained 5.132>1.692 (tcount>ttable). As for the Suggestions for cooperation to be better controlled and secure, by adding to facilities and services, improving planning, financial management, management and administrative systems, to push more transactions and make a new members to join in the cooperative.

Keywords: Income, Welfare of Members, Cooperation. 


\section{PENDAHULUAN}

\subsection{Latar Belakang}

Koperasi ialah sebuah badan usaha yang dimiliki dan dilaksanakan anggotanya bertujuan memenuhi kebutuhan bersama pada ekonomi, sosial, dan budaya. Sesuai pada pasal 33 UUD 1945 ayat 1 berbunyi "perekonomian Indonesia dirangkai untuk bekerja sama (usaha) berdasarkan asas kekeluargaan. Pada UUD 1945 mengatakan usaha yang menganut asas kekeluargaan ialah koperasi. Diharapkan bisa memajukan unit usaha didalamnya secara kuantitas atau kualitas, secara tidak langsung bisa meningkatkan kesejahteraan anggotanya dan tumbuh sebagai organisasi maupun badan usaha yang mampu berperan sesuai UU Perkoperasian No.25 Tahun 1992.

Sebagaimana diketahui bersama, koperasi berbeda dengan badan usaha lainnya, yaitu mempunyai identitas ganda, anggota dan pemilik koperasi juga merupakan pengguna atau pelanggan dari produk atau jasa yang dihasilkan oleh koperasi. Selain partisipasi anggota, koperasi juga dapat berkembang dan tumbuh melalui pengelolan asset yang baik, pinjaman kreditur, dan pengelolaan dana yang baik. Selama tahun 2009-2011, perkembangan koperasi nasional meningkat. Hal terlihat dari beberapa indikator seperti jumlah koperasi, jumlah pegawai, modal, volume usaha, dan nilai SHU.

Terdapat banyak sekali koperasi di Indonesia ini, salah satunya koperasi Viyata Virajati Sesko AD. Koperasi ini adalah koperasi yang anggotanya berupa para pegawai negri dan TNI AD. Sama juga pada koperasi lain, dalam menjalankan kegiatan usahanya perlu menjaga kondisi koperasi dan memperhatikan pendapatan perbulannya, supaya mengetahui seberapa banyak keuntungan yang didapat lalu mengukur sudah berapa pesenkah kenaikan atau penurunan yang didapat dalam perbulan atau pertahunnya.

Dibawah ini merupakan data Pendapatan Koperasi Viyata Virajati Sesko AD Bandung selama 4 tahun terakhir dari tahun 2017-2020:

Table 1. Perkembangan Pendapatan Koperasi Viyata Virajati tahun 2017-2020

\begin{tabular}{|l|l|l|l|l|}
\hline No & Tahun & Pendapatan $($ Rp) & Kenaikan/Penurunan & $\%$ \\
\hline 1 & 2017 & 1.204 .382 .532 & & \\
\hline 2 & 2018 & 1.396 .046 .154 & 191.663 .622 & 13,72 \\
\hline 3 & 2019 & 1.496 .178 .355 & 100.132 .201 & 6,69 \\
\hline 4 & 2020 & 1.740 .720 .817 & $\mathbf{2 4 4 . 5 4 2 . 4 6 2}$ & 14,04 \\
\hline
\end{tabular}

Sumber: Koperasi Viyata Virajati Sesko AD Bandung

Tabel 1. Diatas menunjukkan bahwa selama tahun 2017-2020 terjadi kenaikan atau penurunan terhadap pendapatan. Tahun 2017 jumlah pendapatan sebesar Rp 1.204.382.532, lalu pada tahun 2018 sebesar Rp 1.396.046.154 dan memiliki presentase sebesar 13,72\%, tahun berikutnya 2019 sebesar Rp 1.496.178.355 naik sebesar 6,69\%, dan pada tahun 2020 sebesar Rp 1.740.720.817 naik sebesar 14,04\%. Terjadinya naik atau turun pendapatan koperasi bisa membuat naik dan turunnya kesejahteraan para anggota koperasi tersebut, karena bila pendapatan tersebut naik, yang terjadi adalah kesejahteraan anggota tersebut juga akan naik maka sebaliknya apabila pendapatan tersebut menurun maka kesejahteraan anggota koperasi tersebut bisa menurun. 
Dari hasil penelitian yang pernah dilakukan sebelumnya ternyata terdapat pengaruh pendapatan terhadap kesejahteraan anggotanya, seperti contoh artikel sebagai berikut:

a). Pengaruh Pendapatan Terhadap Kesejahteraan Anggota Koperasi Usaha Manunggal Desa Seresam Kecamatan Seberida Kabupaten Indragiri Hulu. (Jurnal Manajemen dan Bisnis, Volume 8, Nomor 2, Desember 2019, pp. 244-256, dibuat oleh Aris Triyono, Sujawi, R. Marwan Indra Saputra, dari Sekolah Tinggi Imu Ekonomi Indragiri (STIE-1) Rengat)

b). Pengaruh Pendapatan Sektor Pariwisata Terhadap Kesejahteraan Masyarakat Dan Pertumbuhan Ekonomi Lampung Timur (Dibuat oleh: Susi Sulastri dan Eka Pariyanti, STIE Lampung Timur, Jurnal Ilmiah Keuangan dan Perbankan, VOLUME 2, No.2, November 2019, ISSN Cetak: 2621-2439, ISSN Online: 2621-2447)

\subsection{Pokok Permasalahan}

Berdasarkan masalah diatas, lalu penulis tertarik menelaah dan disajikan dalam judul “ Pengaruh Pendapatan Terhadap Kesejahteraan Anggota Koperasi Viyata Virajati Sesko AD Bandung"

\subsection{Pertanyaan Penelitian}

a) Bagaimana gambaran pengaruh pendapatan terhadap kesejahteraan di koperasi Viyata Virajati Sesko AD Bandung?

b) Bagaimana gambaran pengaruh kesejahteraan terhadap pendapatan di koperasi Viyata Virajati Sesko AD Bandung?

c) Bagaimana gambaran pengaruh pendapatan terhadap kesejahteraan anggota koperasi Viyata Virajati Sesko AD Bandung?

d) Apa saja hambatan yang terjadi pada pengaruh pendapatan terhadap kesejahteraan anggota koperasi Viyata Virajati Sesko AD?

e) Upaya apa yang dilakukan untuk menangani permasalahan yang terjadi pada koperasi Viyata Virajati Sesko AD Bandung?

\subsection{Tujuan Penelitian}

a) Untuk memahami pengaruh pendapatan terhadap kesejahteraan di koperasi Viyata Virajati Sesko AD Bandung.

b) Untuk memahami pengaruh kesejahteraan terhadap pendapatan di koperasi Viyata Virajati Sesko AD Bandung.

c) Untuk memahami pengaruh pendapatan terhadap kesejahteraan anggota koperasi Viyata Virajati Sesko AD Bandung.

d) Untuk memahami hambatan yang terjadi pada pendapatan koperasi Viyata Virajati Sesko AD Bandung.

e) Untuk memahami upaya yang telah dilakukan untuk menangani permasalahan pada koperasi Viyata Virajati Sesko AD.

\subsection{Kegunaan Penelitian}

a) Manfaat Teoritis

Pengujian diharapkan bermanfaat untuk mengetahui dan memahami disiplin pegetahuan sosial dan disiplin ilmu yang terkait lainnya khususnya mengenai pengaruh pendapatan terhadap kesejahteraan. Sebagai bahan acuan penelitian selanjutnya ingin mengkaji lebih dalam lagi dan dapat dijadikan sebagai bahan untuk menambah ilmu pegetahuan sebagai metode penelitian. 


\section{b) Manfaat Praktis}

Mengharapkan penelitian bisa bermanfaat untuk penulis, yaitu menambahnya wawasan dan informasi mengenai pengetahuan sosial khususnya mengenai pembelajaran serta menambah pengetahuan penulis dalam bersosialisasi dengan anggota TNI dan masyarakat secara langsung.

1) Bagi lembaga pendidikan dapat dijadikan materi mengenai pendapatan koperasi terhadap kesehateraan.

2) Bagi masyarakat, memberikan informasi mengenai sistem pendapatan koperasi dalam meningkakan kesejahteraan.

3) Bagi masyarakat setempat, memberikan rekomendasi mengenai cara pengembangan koperasi disetiap desa.

\section{KAJIAN PUSTAKA}

\subsection{Pendapatan}

\section{A. Pengertian Pendapatan}

Menurut (Dwi Martani dkk, 2016:204) "Pendapatan ialah aktivitas normal suatu entitas (berwujud) yang mengacu pada istilah yang berbeda" terdapat 5 demensi dari Dwi Martani dkk yaitu: penjualan, bunga, pendapatan jasa, deviden, dan royalty. Menurut (Kieso, W. dan W, 2018) pendapatan adalah aliran keuntungan masuk karena berasal dari kegiatan pada kurun waktu satu periode, bisa berakibat naiknya ekuitas dari kontribusi permodalan.

Pendapatan mempunyai pengaruh yang besar terhadap keberlangsungan sebuah perusahaan, bila makin besar pendapatan makin besar juga kepandaian atau keahlian perusahaan tersebut untuk bisa mendanai seluruh pengeluaran serta aktivitas yang dilaksanakannya. Dapat diukurnya kondisi seseorang menggunakan konsep pemasukan atau pendapatan, dengan menampilkan keseluruhan pendapatan yang diterima seseorang ataupun keluarga sepanjang periode waktu tertentu (Samuelson dan Nordhaus, 2018). Dan terdapat pengertian lain dari pemasukan atau pendapatan tersebut, yaitu jumlah pendapatan yang diperoleh dari karier (pekerjaan) pada kurun waktu tahunan atau bulanan.

\subsection{Kesejahteraan}

\section{A. Pengertian Kesejahteraan}

Tidak mudah bagi Moh. Hatta menjelaskan mengenai kesejahteraan, sulit baginya untuk membedakan kesejahteraan dan kebahagiaan. Tetapi Moh. Hatta menjelaskan kesejahteraan merupakan tingkat perasaan seseorang yang paling tinggi dari pada kebahagian, dengan membiasakan jiwa yang tenang, keadilan di dalam hidup, dan terbebas tanpa adanya bahaya kemiskinan.

Sedangkan menurut (Diener \& Lucas, 2021) "kesejahteraan merupakan kesenangan subjektif individu atas baik dan buruk dalam hidup" konsep ini mencakup tiga komponen yaitu kebahagiaan, kepuasan hidup, dan adanya emosi positif. Kesejahteraan adalah keadaan dimana masyarakat dalam kehidupan yang bisa dilihat dari taraf hidup masyarakat (Badrudin, 2021).

\subsection{Koperasi}

\section{A. Pengertian Koperasi}

Koperasi adalah sekelompok individu secara lapang dada untuk mempersatu dalam mewujudkan kesejahteraan perdagangan secara demokratis (Rudianto, 2015). Menurut 
(Chaniago, 2021) Koperasi adalah perkumpulan yang terdiri dari perseorangan atau badan hukum yang berusaha untuk meningkatkan kesejahteraan para anggotanya dengan bekerja sama secara kekeluargaan.

Koperasi sangat membantu dalam perekonomian masyarakat karena memiliki bunga yang sangat rendah daripada bank atau instansi lain. Seperti halnya di koperasi Viyata Virajati Sesko AD Bandung disitu juga menerima simpan pinjam dari masyarakat luar tetapi harus membawa persyaratan yang telah di tetapkan.

\section{METODE}

\subsection{Pengertian Metode}

Upaya yang harus dilalui dengan cara penelitian yang dilaksanakan secara sistimatis. (Sugiyono, 2018) "Metode penelitian bisa dijalankan untuk mendapatkan hasil yang valid atau jelas dengan maksud bisa didapatkan, dikembangkan, dan agar terbukti suatu pengetahuan dapat digunakan untuk memahami dan mengantisipasi permasalah." Data yang telah didapat semuanya lalu dikupas secara kuantitatif memakai statistic deskriptif yang disebut hipotesis, untuk menunjukkan antara terbukti atau tidak.

\subsection{Definisi Operasional Variabel}

"Operasional variable adalah nilai yang berasal dari obyek atau aktivitas tertentu yang telah diresmikan dari peneliti buat dipelajari, sesudah itu ditarik kesimpulanya" Sugiyono (2015). Berdasar judul yang penulis ambil, penulis memakai 2 variabel yaitu pengaruh pendapatan sebagai variabel (X) dan kesejahteraan sebagai variabel (Y)

\subsection{Populasi dan Sampel}

"Populasi ialah daerah terdapat obyek/subjek yang karakteristiknya telah diresmikan peneliti buat dipelajari dan kemudian disimpulkannya" (Sugiyono, 2015). Terdapat populasi 700 anggota koperasi Viyata Virajati Sesko AD Bandung dan terdapat sampel sebesar 35 dari anggota koperasi.

Sampel adalah sebagian jumlah karakteristik yang dipunyai populasi itu sendiri. Disini peneliti menggunakan rumus untuk mendapatkan besaran sampel, serta bisa juga rumus Slovin yang bisa dikerjakan dengan mudah memakai rumus : $\mathbf{n}=\mathbf{N} /\left(\mathbf{1}+\mathbf{N} .(\mathbf{e})^{\mathbf{2}}\right)$

\subsection{Jenis dan Sumber Data}

\section{A. Jenis Data}

Jenis data yang dipakai yaitu kuantitatif, merupakan keterkaitan secara langsung bersama bilangan-bilangan.

\section{B. Sumber Data}

\section{Data Primer}

Data ini dibuat oleh penulis sendiri yang berasal hasil kuisioner yang disebarkan kepada anggota koperasi Viyata Virajati Sesko AD.

2. Data Sekunder

(Sugiyono, 2016: 225) "Data Sekunder ialah berasal dari penelitian lewat perantara orang lain (tak langsung) dan dokumen-dokumen. Lalu pada data ini sebagai tambahan untuk melengkapi bila ada yang kurang dari data primer tersebut" dan penulis mengambil data sekunder ini melalui cara kuisioner, lalu menggunakan metode kuantitatif dan menggunakan 
pendekatan deskriptif asosiasi caranya menyebarkan kuisioner tersebut kepada anggota koperasi Viyata Virajati Sesko AD Bandung.

\subsection{Teknik Analisis Data}

\section{a). Metode Kuisioner}

Kuisioner yaitu cara memberikan selebaran yang isinya pertanyaan tertulis untuk responden kemudian dijawab dengan cara ceklis yang berkaitan tentang Pengaruh Pendapatan Terhadap Kesejahteraan Anggota Koperasi Viyata Virajati Sesko AD Bandung. Untuk membuat kuisioner tersebut penulis memakai materi dari landasan teori pendapatan dan kesejahteraan.

\section{b). Uji Validitas dan Reabilitas}

Uji validitas ialah pengujian yang dipakai untuk memperlihatkan atau membuktikan alat ukur yang digunakan pada pengukuran efektifitas kuesioner. Apabila pertanyaan kuisioner tersebut dapat menjelaskan sesuatu yang akan diukur oleh kuisioner, lalu kuesioner tersebut dapat disebut efektif. Dari hasil pengukuran harus bisa diandalkan karena harus memiliki tingkat konsistensi dan stabilitas tertentu. Uji reabilitas adalah informasi untuk mengungkapkan kebenaran agar lebih dipercaya data tersebut, seperti mengamati pada cronbach's alpha $>$ 0,6 lalu pertanyaan tersebut bisa dinyatakan realiabel untuk dipakai pada pengkajian.

\section{c). Uji Normalitas}

Uji normalitas digunakan untuk mengukur perbandingan data empiris dan data yang berdistribusi normal secara teoritis. Data berdistribusi normal teoritis dan data empiris memiliki mean dan standar deviasi yang sama. Data yang terdistribusi normal merupakan salah satu syarat data berparameter, sehingga data tersebut memiliki karakter empiris yang mewakili keseluruhan.

Untuk pengambilan hasil (keputusan) pengujian normalitas adalah apabila nilai signifikansi $\geq 0,05$ maka data tersebut berdistribusi normal, sebaliknya jika nilai signifikan $\leq$ 0,05 maka data berdistribusi tidak normal. Distribusi normal secara otomatis akan membentuk garis diagonal, dan data residual yang di plot akan diperbandingkan dengan garis diagonal. Menguji menggunakan p-plot yang memakai SPSS V.28.0

\section{d). Uji Regresi Linier Sederhana}

"Analisis regresi dipakai untuk memprediksi tingkat perubahan pada nilai variabel dependen, apabila nilai pada variabel independen diubah atau ditambah atau dikurangi. Manfaat regresi hasil analisisnya adalah untuk memutuskan apakah kenaikan atau penurunan variabel dependen bisa ditentukan melalui meningkatkan variabel independen" Sugiyono (2018)

Uji regresi linier sederhana memiliki beberapa tujuan yaitu:

a. Menghitung estimasi rata-rata berdasarkan nilai variabel bebas dan nilai terikat

b. Menguji hipotetesis yang bergantung pada karakteristik

\section{e). Uji Corelasi Product Moment Pearson}

Tujuan penggunaan perhitungan korelasi ialah untuk mengetahui hubungan antara variabel $\mathrm{X}$ dan variabel Y yang akan diteliti. Hubungan yang dimaksud ialah apakah terdapat hubungan positif atau negative. Jika penaikan atau penurunan $\mathrm{X}$ biasanya disertai dengan penaikan atau penurunan $\mathrm{Y}$, maka hubungan antara $\mathrm{X}$ dan $\mathrm{Y}$ dikatakan positif. Metric yang 
digunakan untuk menentukan apakah hubungan antara X dan Y kuat disebut ( $\mathrm{r}$ ) atau koefisien korelasi.

\section{f). Uji Koefisien Determinasi}

Untuk mengetahui besarnya kontribusi variabel bebas terhadap perubahan (kenaikan/penurunan) variabel terikat digunakan koefisien determinasi, rumusnya $\mathbf{K D}=\mathbf{r}^{2} \mathbf{x}$ $100 \%$

\section{g). Uji Hipotesis Melalui Uji T Dan Uji F}

\section{Uji T}

Yaitu dengan melakukan uji parsial terhadap koefisien regresi dengan mengasumsikan bahwa variabel independen lainnya dianggap konstan untuk menentukan signifikasi parsial pengaruh variabel independen terhadap variabel dependen. Maka syarat harus memenuhi Uji T sebagai berikut:

- $t_{\text {hirung }}>\mathrm{t}_{\text {tabel }}$ a jadi, Ha $: \beta \neq 0$, berpengaruh signifikan

- $\mathrm{t}_{\text {hitung }}<\mathrm{t}_{\text {tabel, }}$, jadi Ho : $\beta=0$, tidak berpengaruh signifikan

\section{Uji F}

Yaitu menguji simultan kepada koefisien regresi, tujuannya untuk melihat variabel dependen terhadap independen yang mempengaruhi variabel dependen secara berbarengan. Maka harus memenuhi Uji F sebagai berikut:

- $\mathrm{f}_{\text {hitung }}>\mathrm{f}_{\text {tabel }}$ a jadi, Ha $: \beta \neq 0$, memiliki pengaruh

- $t_{\text {hitung }}<t_{\text {tabel }}$ maka Ho $: \beta=0$, tidak memiliki pengaruh

\section{HASIL DAN PEMBAHASAN}

\subsection{Hasil}

\section{A). Hasil Penelitian}

Menyuguhkan hasil pengkajian dan pembahasan dengan menyebarkan selebaran kuisioner dan untuk mengetahui tanggapan responden terhadap pengaruh pendapatan terhadap kesejahteraan anggota koperasi Viyata Virajati Sesko AD Bandung.

\section{B). Profil Responden}

Responden yang mengerjakan kuisioner ini terdiri 35 responden dan terdapat 29 orang laki-laki dan 6 orang perempuan, yaitu semuanya berupa anggota koperasi. Umur responden dengan rentang umur 21-25 $=3$ orang, 26-30 $=13$ orang, 31-35 $=6$ orang, $36-40=7$ orang, 41$45=2$ orang, $>46=4$ orang. Pendidikan respondenya dari tingkat SMA/SMK $=25$ orang, S1 $=4$ orang, dan $\mathrm{S} 2=1$ orang. Semua responden memiliki pekerjaan yang sama yaitu TNI AD.

\section{Tanggapan responden tentang variable $X$ (Pendapatan)}

Table.1 Tanggapan Responden Tentang Pendapatan (X)

\begin{tabular}{|l|l|l|l|l|l|l|l|l|}
\hline \multirow{2}{*}{ No } & \multirow{2}{*}{ Indikator } & \multicolumn{5}{|c|}{ Skor } & Jumlah & Rata- \\
\cline { 3 - 7 } & & STS & TS & RR & S & ST & & rata \\
\hline 1 & P1 & 0 & 0 & 1 & 19 & 15 & 154 & 4,4 \\
\hline 2 & P2 & 0 & 0 & 1 & 19 & 15 & 154 & 4,4 \\
\hline 3 & P3 & 0 & 0 & 2 & 20 & 13 & 151 & 4,314 \\
\hline 4 & P4 & 0 & 0 & 2 & 18 & 15 & 153 & 4,371 \\
\hline 5 & P5 & 0 & 0 & 1 & 22 & 12 & 151 & 4,314 \\
\hline
\end{tabular}




\begin{tabular}{|l|l|l|l|l|l|l|l|l|}
\hline 6 & P6 & 0 & 0 & 0 & 17 & 18 & 158 & 4,514 \\
\hline
\end{tabular}
(Pendapatan) Adalah no.1 (Barang dagangan yang dijual di Koperasi Viyata Virajati Sesko AD Bandung sudah memenuhi kriteria penjualan yaitu menjual makanan kemasan dan perlengkapan atribut TNI AD) mendapatkan pilihan yang paling banyak yaitu rata-rata 4,514. Lalu tanggapan responden no.3 (Pendapatan yang didapat di Koperasi Viyata Virajati sudah membuat anggota koperasi sejahtera) dan no.5 (Barang yang dijual di koprasi harganya lebih murah daripada di toko-toko luar) mendapatkan respon dari responden yang rendah yaitu 4,314 .

2. Tanggapan responden tentang variable $\mathbf{Y}$ (Kesejahteraan)

Tabel.2 Tanggapan Responden Tentang Kesejahteraan (Y)

\begin{tabular}{|l|l|l|l|l|l|l|l|l|}
\hline \multirow{2}{*}{ No } & Indikator & \multicolumn{5}{|c|}{ Skor } & Jumlah & $\begin{array}{l}\text { Rata- } \\
\text { rata }\end{array}$ \\
\cline { 3 - 7 } & & STS & TS & RR & S & ST & & 187 \\
\hline 1 & P1 & 0 & 0 & 1 & 16 & 18 & 157 & 4,485 \\
\hline 2 & P2 & 0 & 0 & 2 & 17 & 16 & 154 & 4,4 \\
\hline 3 & P3 & 0 & 0 & 3 & 21 & 11 & 148 & 4,228 \\
\hline 4 & P4 & 0 & 0 & 1 & 20 & 14 & 161 & 4,6 \\
\hline 5 & P5 & 0 & 0 & 0 & 25 & 10 & 150 & 4,285 \\
\hline 6 & P6 & 0 & 0 & 1 & 19 & 15 & 154 & 4,4 \\
\hline 7 & P7 & 0 & 0 & 3 & 21 & 11 & 148 & 4,228 \\
\hline 8 & P8 & 0 & 0 & 1 & 16 & 18 & 157 & 4,485 \\
\hline 9 & P9 & 0 & 0 & 1 & 16 & 18 & 157 & 4,485 \\
\hline
\end{tabular}

Dari table diatas bisa dilihat jumlah jawaban responden mengenai variable $\mathrm{Y}$ (Kesejahteraan). Untuk pernyataan no.4 (Masyarakat antusias membeli barang di toko Koperasi Viyata Virajati Sesko AD Bandung karena harganya terjangkau dan semuanya tertata dengan baik dan bersih) mendapatkan pilihan yang paling banyak yaitu rata-rata 4,6 lalu untuk no. 3 yaitu dengan pernyataan (apabila ada barang atau makanan yang expired petugasnya langsung menggati barang yang baru) dan no.7 dengan pernyataan (para masyarakat atau anggota koperasi sangat menyukai belanja di toko koperasi karena pelayanannya sangat baik dan sopan) mendapatkan pilihan yang sangat rendah yaitu 4,228.

\section{C). Uji Validitas dan Reabilitas}

\section{Uji Validitas}

a. Uji Validitas (Pendapatan)

Table.3 Uji Validitas Pendapatan (X)

\section{Correlations}

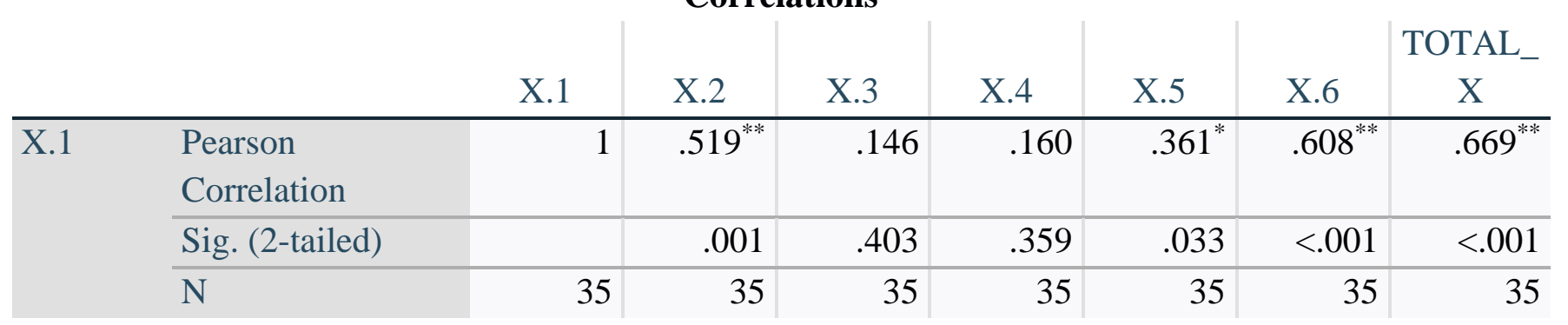




\section{[ACCOUNTING GLOBAL JOURNAL] E ISSN 2623-1778}

\begin{tabular}{|c|c|c|c|c|c|c|c|c|}
\hline \multirow[t]{3}{*}{ X.2 } & $\begin{array}{l}\text { Pearson } \\
\text { Correlation }\end{array}$ & $.519^{* *}$ & 1 & .237 & $.427^{*}$ & .261 & $.503^{* *}$ & $.716^{* *}$ \\
\hline & Sig. (2-tailed) & .001 & & .170 & .011 & .130 & .002 & $<.001$ \\
\hline & $\mathrm{N}$ & 35 & 35 & 35 & 35 & 35 & 35 & 35 \\
\hline \multirow[t]{3}{*}{ X.3 } & $\begin{array}{l}\text { Pearson } \\
\text { Correlation }\end{array}$ & .146 & .237 & 1 & $.415^{*}$ & $.433^{* *}$ & .233 & $.612^{* *}$ \\
\hline & Sig. (2-tailed) & .403 & .170 & & .013 & .009 & .178 & $<.001$ \\
\hline & $\mathrm{N}$ & 35 & 35 & 35 & 35 & 35 & 35 & 35 \\
\hline \multirow[t]{3}{*}{ X.4 } & $\begin{array}{l}\text { Pearson } \\
\text { Correlation }\end{array}$ & .160 & $.427^{*}$ & $.415^{*}$ & 1 & $.456^{* *}$ & .224 & $.669^{* *}$ \\
\hline & Sig. (2-tailed) & .359 & .011 & .013 & & .006 & 195 & $<.001$ \\
\hline & $\mathrm{N}$ & 35 & 35 & 35 & 35 & 35 & 35 & 35 \\
\hline \multirow[t]{3}{*}{ X.5 } & $\begin{array}{l}\text { Pearson } \\
\text { Correlation }\end{array}$ & $.361^{*}$ & .261 & $.433^{* *}$ & $.456^{* *}$ & 1 & $.475^{* *}$ & $.722^{* *}$ \\
\hline & Sig. (2-tailed) & .033 & .130 & .009 & .006 & & .004 & $<.001$ \\
\hline & $\mathrm{N}$ & 35 & 35 & 35 & 35 & 35 & 35 & 35 \\
\hline \multirow[t]{3}{*}{ X.6 } & $\begin{array}{l}\text { Pearson } \\
\text { Correlation }\end{array}$ & $.608^{* *}$ & $.503^{* *}$ & .233 & .224 & $.475^{* *}$ & 1 & $.723^{* *}$ \\
\hline & Sig. (2-tailed) & $<.001$ & .002 & .178 & 195 & .004 & & $<.001$ \\
\hline & $\mathrm{N}$ & 35 & 35 & 35 & 35 & 35 & 35 & 35 \\
\hline \multirow[t]{3}{*}{$\begin{array}{l}\text { TOTAL_ } \\
\mathrm{X}\end{array}$} & $\begin{array}{l}\text { Pearson } \\
\text { Correlation }\end{array}$ & $.669^{* *}$ & $.716^{* *}$ & $.612^{\text {** }}$ & $.669^{* *}$ & $.722^{* * *}$ & $.723^{* *}$ & 1 \\
\hline & Sig. (2-tailed) & $<.001$ & $<.001$ & $<.001$ & $<.001$ & $<.001$ & $<.001$ & \\
\hline & $\mathrm{N}$ & 35 & 35 & 35 & 35 & 35 & 35 & 35 \\
\hline
\end{tabular}

**. Correlation is significant at the 0.01 level (2-tailed).

*. Correlation is significant at the 0.05 level (2-tailed).

\begin{tabular}{|c|c|c|c|c|c|c|}
\hline No & $\mathbf{1}$ & $\mathbf{2}$ & $\mathbf{3}$ & $\mathbf{4}$ & $\mathbf{5}$ & $\mathbf{6}$ \\
\hline Rhitung & 0,669 & 0,716 & 0,612 & 0,669 & 0,722 & 0,723 \\
\hline
\end{tabular}

Berdasarkan uji validitas diatas untuk variabel pendapatan menunjukkan hasilnya signifikan (valid). Karena $r$ hitung memiiki nilai yang besar dibanding $r$ table $(0,338)$ dan memiliki nilai sign kurang dari $(0,05)$. Sama halnya yang variable kesejahteraan (Y) dan hasilnya adalah:

b. Uji Validitas (Kesejahteraan)

Table.4 Uji Validitas Kesejahteraan (Y)

Correlations

\begin{tabular}{|l|l|l|l|l|l|l|l|l|l|}
\hline Y.1 & Y.2 & Y.3 & Y.4 & Y.5 & Y.6 & Y.7 & Y.8 & Y.9 & L_Y \\
\hline
\end{tabular}

\begin{tabular}{|l|l|l|l|l|l|l|l|l|l|l|l|}
\hline Y.1 & $\begin{array}{l}\text { Pearson } \\
\text { Correlation }\end{array}$ & 1 & $.797^{* *}$ & $.447^{* *}$ & $.544^{* *}$ & $.473^{* *}$ & $.492^{* *}$ & $.447^{* *}$ & 1.000 & $1.000^{*}$ & $.860^{* *}$ \\
\cline { 2 - 8 } & Sig. (2-tailed) & $<.001$ & .007 & $<.001$ & .004 & .003 & .007 & .000 & .000 & $<.001$ \\
\hline
\end{tabular}




\section{[ACCOUNTING GLOBAL JOURNAL] E ISSN 2623-1778}

\begin{tabular}{|c|c|c|c|c|c|c|c|c|c|c|c|}
\hline & $\mathrm{N}$ & 35 & 35 & 35 & 35 & 35 & 35 & 35 & 35 & 35 & 35 \\
\hline \multirow[t]{3}{*}{ Y.2 } & $\begin{array}{l}\text { Pearson } \\
\text { Correlation }\end{array}$ & $.797^{* * *}$ & 1 & $.554^{* * *}$ & $.605^{* *}$ & $.425^{*}$ & $.564^{* *}$ & $.554^{* *}$ & $.797^{* *}$ & $.797^{* *}$ & $.849^{* *}$ \\
\hline & Sig. (2-tailed) & $<.001$ & & $<.001$ & $<.001$ & 011 & $<.001$ & $<.001$ & $<.001$ & $<.001$ & $<.001$ \\
\hline & $\mathrm{N}$ & 35 & 35 & 35 & 35 & 35 & 35 & 35 & 35 & 35 & 35 \\
\hline \multirow[t]{3}{*}{ Y.3 } & $\begin{array}{l}\text { Pearson } \\
\text { Correlation }\end{array}$ & $.447^{* *}$ & $.554^{* *}$ & 1 & $.811^{* *}$ & $.506^{* *}$ & $.516^{* *}$ & $\begin{array}{r}1.000 \\
* *\end{array}$ & $.447^{* *}$ & $.447^{* * *}$ & $.800^{* *}$ \\
\hline & Sig. (2-tailed) & .007 & $<.001$ & & $<.001$ & .002 & .002 & . 000 & .007 & .007 & $<.001$ \\
\hline & $\mathrm{N}$ & 35 & 35 & 35 & 35 & 35 & 35 & 35 & 35 & 35 & 35 \\
\hline \multirow[t]{3}{*}{ Y.4 } & $\begin{array}{l}\text { Pearson } \\
\text { Correlation }\end{array}$ & $.544^{* *}$ & $.605^{* *}$ & $.811^{* *}$ & 1 & $.503^{* *}$ & $.467^{* *}$ & $.811^{* *}$ & $.544^{* *}$ & $.544^{* *}$ & $.810^{* * *}$ \\
\hline & Sig. (2-tailed) & $<.001$ & $<.001$ & $<.001$ & & .002 & .005 & $<.001$ & $<.001$ & $<.001$ & $<.001$ \\
\hline & $\mathrm{N}$ & 35 & 35 & 35 & 35 & 35 & 35 & 35 & 35 & 35 & 35 \\
\hline \multirow[t]{3}{*}{ Y.5 } & $\begin{array}{l}\text { Pearson } \\
\text { Correlation }\end{array}$ & $.473^{* *}$ & $.425^{*}$ & $.506^{* *}$ & $.503^{* *}$ & 1 & $.580^{* *}$ & $.506^{* *}$ & $.473^{* *}$ & $.473^{* * *}$ & $.668^{* *}$ \\
\hline & Sig. (2-tailed) & .004 & .011 & .002 & .002 & & $<.001$ & .002 & .004 & . 004 & $<.001$ \\
\hline & $\mathrm{N}$ & 35 & 35 & 35 & 35 & 35 & 35 & 35 & 35 & 35 & 35 \\
\hline \multirow[t]{3}{*}{ Y.6 } & $\begin{array}{l}\text { Pearson } \\
\text { Correlation }\end{array}$ & $.492^{* *}$ & $.564^{* *}$ & $.516^{* *}$ & $.467^{* *}$ & $.580^{* *}$ & 1 & $.516^{* *}$ & $.492^{* *}$ & $.492^{* *}$ & $.705^{* *}$ \\
\hline & Sig. (2-tailed) & .003 & $<.001$ & .002 & .005 & $<.001$ & & .002 & .003 & .003 & $<.001$ \\
\hline & $\mathrm{N}$ & 35 & 35 & 35 & 35 & 35 & 35 & 35 & 35 & 35 & 35 \\
\hline \multirow[t]{3}{*}{ Y.7 } & $\begin{array}{l}\text { Pearson } \\
\text { Correlation }\end{array}$ & $.447^{* *}$ & $.554^{* *}$ & $1.000^{*}$ & $.811^{* *}$ & $.506^{* *}$ & $.516^{* *}$ & 1 & $.447^{* *}$ & $.447^{* *}$ & $.800^{* *}$ \\
\hline & Sig. (2-tailed) & .007 & $<.001$ & .000 & $<.001$ & .002 & .002 & & .007 & .007 & $<.001$ \\
\hline & $\mathrm{N}$ & 35 & 35 & 35 & 35 & 35 & 35 & 35 & 35 & 35 & 35 \\
\hline \multirow[t]{3}{*}{ Y.8 } & $\begin{array}{l}\text { Pearson } \\
\text { Correlation }\end{array}$ & $\begin{array}{r}1.000^{*} \\
*\end{array}$ & $.797^{* * *}$ & $.447^{* * *}$ & $.544^{* *}$ & $.473^{* *}$ & $.492^{* *}$ & $.447^{* *}$ & 1 & $\begin{array}{r}1.000^{*} \\
*\end{array}$ & $.860^{* * *}$ \\
\hline & Sig. (2-tailed) & .000 & $<.001$ & .007 & $<.001$ & .004 & .003 & .007 & & .000 & $<.001$ \\
\hline & $\mathrm{N}$ & 35 & 35 & 35 & 35 & 35 & 35 & 35 & 35 & 35 & 35 \\
\hline \multirow[t]{3}{*}{ Y.9 } & $\begin{array}{l}\text { Pearson } \\
\text { Correlation }\end{array}$ & $1.000^{*}$ & $.797^{* *}$ & $.447^{* *}$ & $.544^{* *}$ & $.473^{* *}$ & $.492^{* * *}$ & $.447^{* *}$ & 1.000 & 1 & $.860^{* *}$ \\
\hline & Sig. (2-tailed) & .000 & $<.001$ & .007 & $<.001$ & .004 & .003 & .007 & .000 & & $<.001$ \\
\hline & $\mathrm{N}$ & 35 & 35 & 35 & 35 & 35 & 35 & 35 & 35 & 35 & 35 \\
\hline \multirow[t]{3}{*}{$\begin{array}{l}\text { TOTAL } \\
\mathrm{Y}\end{array}$} & $\begin{array}{l}\text { Pearson } \\
\text { Correlation }\end{array}$ & $.860^{* *}$ & $.849^{* *}$ & $.800^{* *}$ & $.810^{* * *}$ & $.668^{* *}$ & $.705^{* *}$ & $.800^{* * *}$ & $.860^{* *}$ & $.860^{* *}$ & 1 \\
\hline & Sig. (2-tailed) & $<.001$ & $<.001$ & $<.001$ & $<.001$ & $<.001$ & $<.001$ & $<.001$ & $<.001$ & $<.001$ & \\
\hline & $\mathrm{N}$ & 35 & 35 & 35 & 35 & 35 & 35 & 35 & 35 & 35 & 35 \\
\hline
\end{tabular}

**. Correlation is significant at the 0.01 level (2-tailed).

*. Correlation is significant at the 0.05 level (2-tailed). 


\begin{tabular}{|l|l|l|l|l|l|l|l|l|l|}
\hline No & 1 & 2 & 3 & 4 & 5 & 6 & 7 & 8 & 9 \\
\hline Rhitung & 0,860 & 0,849 & 0,800 & 0,810 & 0,668 & 0,705 & 0,800 & 0,860 & 0,860 \\
\hline
\end{tabular}

\section{Uji Reabilitas}

a. Uji Reabilitas (Pendapatan)

Table.5 Uji Reabilitas Variabel (X) Pendapatan

Case Processing Summary

\begin{tabular}{|c|c|c|c|}
\hline \multirow{2}{*}{ Cases } & \multicolumn{2}{|c|}{$\mathrm{N}$} & $\%$ \\
\hline & Valid & 35 & 100.0 \\
\hline & Excluded $^{\mathrm{a}}$ & 0 & .0 \\
\hline & Total & 35 & 100.0 \\
\hline
\end{tabular}

a. Listwise deletion based on all variables in the procedure.

\section{Reliability Statistics}

Cronbach's

\begin{tabular}{r|r} 
Alpha & N of Items \\
\hline .771 & 6 \\
\hline
\end{tabular}

Dari table diatas membuktikan bahwa nilai Cronbach's Alpha memiliki nilai lebih besar dari 0,6 maka menujukkan variable pendapatan bisa disebut VALID. Sama halnya yang dibawah yaitu table variable (Y) disebut VALID juga.

\section{b. Uji Reabilitas (Kesejahteraan)}

Tabel.6 Uji Reabilitas Variabel (Y) Kesejahteraan

Case Processing Summary

\begin{tabular}{clc|c} 
& & $\mathrm{N}$ & $\%$ \\
\hline \multirow{3}{*}{ Cases } & Valid & 35 & 100.0 \\
\cline { 2 - 4 } & Excluded $^{\mathrm{a}}$ & 0 & .0 \\
\cline { 2 - 4 } & Total & 35 & 100.0 \\
\hline
\end{tabular}

a. Listwise deletion based on all variables in the procedure.

\section{Reliability Statistics}

Cronbach's

\begin{tabular}{r|r} 
Alpha & N of Items \\
\hline .931 & 9 \\
\hline
\end{tabular}

\subsection{Hasil Uji Analisis}

\section{A. Uji Normalitas}




\section{Gambar.1 Uji Normalitas P-Plot}

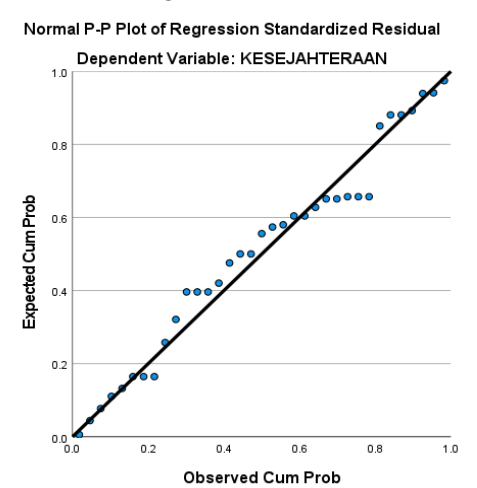

Sumber. Hasil pengolahan data 2021 dengan spss V28.0 for windows

Dari gambar diatas bisa dilihat dari titi-titik yang menebar pada garis diagonal lalu mengarah bentuk garis diagonal, dan disebut terdistribusi normal.

\section{B. Uji Regresi Linier Sederhana}

Table.7 Uji Regresi Linier Sederhana Coefficients $^{\mathbf{a}}$

\begin{tabular}{|c|c|c|c|c|c|c|c|c|}
\hline \multirow{2}{*}{\multicolumn{2}{|c|}{ Model }} & \multicolumn{2}{|c|}{$\begin{array}{c}\text { Unstandardized } \\
\text { Coefficients }\end{array}$} & \multirow{2}{*}{$\begin{array}{c}\text { Standardized } \\
\text { Coefficients } \\
\text { Beta }\end{array}$} & \multirow[b]{2}{*}{$\mathrm{t}$} & \multirow[b]{2}{*}{ Sig. } & \multicolumn{2}{|c|}{$\begin{array}{c}\text { Collinearity } \\
\text { Statistics }\end{array}$} \\
\hline & & B & Std. Error & & & & $\begin{array}{c}\text { Toleranc } \\
\mathrm{e}\end{array}$ & VIF \\
\hline \multirow[t]{2}{*}{1} & (Constant) & 8.055 & 6.124 & & 1.315 & .198 & & \\
\hline & $\begin{array}{l}\text { PENDAPAT } \\
\text { AN }\end{array}$ & 1.190 & .232 & .666 & 5.132 & $<.001$ & 1.000 & 1.000 \\
\hline
\end{tabular}

a. Dependent Variable: KESEJAHTERAAN

Sumber. Hasil pengolahan data 2021 dengan spss V28.0 for windows

Pada table.7 bahwa nilai variabel kesejahteraan adalah 8,055 lalu nilai pendapatan (B) adalah 1,190 dan perbandingan regresinya bisa ditulis:

$\mathbf{Y}=\mathbf{a}+\mathbf{B x}$

$Y=8,055+1,190 X$

Koefisien b dinamakan koefisien regresi, yang mewakili rata-rata perubahan variabel $Y$ untuk setiap unit perubahan variabel $X$. perubahan ini meningkat ketika b positif, dan menurun apabila $\mathrm{b}$ negative. Maka dari persamaan tersebut dapat diterjemahkan menjadi:

a. konstanta sebesar 8,055 berarti bila tidak ada nilai pendapatan terhadap kesejahteraan sebesar 8,055.

b. koefisien regresi (X) sebesar 1,190 artinya pada penambahan 1 nilai pendapatan, lalu nilai kesejahteraan tersebut adalah 1,90

\section{Uji Korelasi Produk Moment Pearson}

Tabel.8 Uji Korelasi Produk Moment Pearson

Correlations

PENDAPATA KESEJAHTERAA

$\mathrm{N}$ $\mathrm{N}$ 


\begin{tabular}{|c|c|c|c|}
\hline \multirow[t]{3}{*}{ PENDAPATAN } & $\begin{array}{l}\text { Pearson } \\
\text { Correlation }\end{array}$ & 1 & $.666^{* *}$ \\
\hline & Sig. (2-tailed) & & $<.001$ \\
\hline & $\mathrm{N}$ & 35 & 35 \\
\hline \multirow{4}{*}{$\begin{array}{l}\text { KESEJAHTERAA } \\
\mathrm{N}\end{array}$} & Pearson & $.666^{* *}$ & 1 \\
\hline & Correlation & & \\
\hline & Sig. (2-tailed) & $<.001$ & \\
\hline & $\mathrm{N}$ & 35 & 35 \\
\hline
\end{tabular}

Hasil diatas dapat kita lihat terdapat hubungan antara pengaruh pendapatan (X) terhadap kesejahteraan (Y) yaitu sebesar 0,666 yang artinya memiliki ikatan yang KUAT. Dengan nilai signifikasi sebesar 0,001 $<0,05$ yang menunjukan bahwa memiliki hubungan antara pendapatan dengan kesejahteraan anggota. Hubungan tersebut berada dalam kategori kuat seperti dapat dilihat dari pedoman derajat dibawah ini:

\begin{tabular}{|c|c|}
\hline Interval Korelasi & Tingkat Hubungan \\
\hline $0,00-0,199$ & Sangat Rendah \\
\hline $0,20-0,399$ & Rendah \\
\hline $0,40-0,599$ & Sedang \\
\hline $0,60-0,799$ & Kuat \\
\hline $0,80-0,1000$ & Sangat Kuat \\
\hline
\end{tabular}

\section{Uji Koefisien Determinasi}

\section{Table.9 Uji Koefisien Determinasi Model Summary ${ }^{b}$}

\begin{tabular}{ll|r|r|r} 
Model & R & R Square & \multicolumn{1}{|c}{$\begin{array}{c}\text { Adjusted R } \\
\text { Square }\end{array}$} & $\begin{array}{l}\text { Std. Error of } \\
\text { the Estimate }\end{array}$ \\
\hline 1 & $.666^{\mathrm{a}}$ & .444 & .427 & 3.07257 \\
\hline
\end{tabular}

a. Predictors: (Constant), PENDAPATAN

b. Dependent Variable: KESEJAHTERAAN

Sumber. Hasil pengolahan data 2021 dengan spss V28.0 for windows

Uji koefisien determinasi, untuk menganalisis secara simultan seberapa kuat hubungan antara variabel independen dan dependen, atau apakah ada pengaruh antara Pendapatan (X) dan Kesejahteraan (Y), dilakukan uji kepastian menggunakan SPSS Statistical.

Table diatas menunjukkan seberapa kuat hubungan antara independen dengan dependen dengan ada tidaknya hubungan Pendapatan (X) dengan Kesejahteraan (Y). menunjukkan nilai (R) Pengaruh Pendapatan Terhadap Kesejahteraan Anggota Koperasi sebesar 0,666 dan diatas juga sudah dijelaskan nilai interval koefisien antara $(0,60-0,799)$ dinyatakan mempunyai hubungan yang kuat. Dan (R2) diperoleh sebesar 0,444 (44,4\%) yang 
berarti Kesejateraan Anggota Koperasi Viyata Virajati Sesko AD Bandung dipengaruhi oleh Pendapatan. Lalu untuk sisanya yang tidak diteliti dari faktor lain sebesar 55,6\% .

E. Uji Hipotesis (Uji T da Uji Y)

\section{Uji Significant $\mathbf{T}$}

Tabel.10 Uji Significant $T$

\section{Coefficients $^{\mathrm{a}}$}

\begin{tabular}{|c|c|c|c|c|c|c|c|c|}
\hline \multirow{2}{*}{\multicolumn{2}{|c|}{ Model }} & \multicolumn{2}{|c|}{$\begin{array}{l}\text { Unstandardized } \\
\text { Coefficients }\end{array}$} & \multirow{2}{*}{$\begin{array}{c}\text { Standardized } \\
\text { Coefficients } \\
\text { Beta }\end{array}$} & \multirow[b]{2}{*}{$\mathrm{t}$} & \multirow[b]{2}{*}{ Sig. } & \multicolumn{2}{|c|}{$\begin{array}{c}\text { Collinearity } \\
\text { Statistics }\end{array}$} \\
\hline & & $\mathrm{B}$ & Std. Error & & & & $\begin{array}{c}\text { Toleranc } \\
\mathrm{e}\end{array}$ & VIF \\
\hline \multirow[t]{2}{*}{1} & (Constant) & 8.055 & 6.124 & & 1.315 & .198 & & \\
\hline & PENDAPATAN & 1.190 & .232 & .666 & 5.132 & $<.001$ & 1.000 & 1.000 \\
\hline
\end{tabular}

a. Dependent Variable: KESEJAHTERAAN

Sumber. Hasil pengolahan data 2021 dengan spss V28.0 for windows

Dari hasil uji diatas menunjukkan thitung sebesar 5,132 yang terdapat pada variabel Pendapatan. Terdapat 0,05 yang menunjukkan hasil pada tingkat kepercayaan, dan untuk derajat kebebasannya $\mathrm{n}-2=33$ yang didapat $\mathrm{t}$ table sebesar 1,692 untuk mendapatkan keejahteraan harus diadakannya perbandingan antara thitung dan $\mathrm{t}$ table. Lalu untuk $\mathrm{t}$ hitung pada Pendapatan sebesar 5,132 $\geq 1,692$ (t table). Lalu kemudian hasilnya H1 diterima dan H0 ditolak, artinya Pendapatan Terhadap Kesejahteraan Anggota Koperasi Viyata Virajati Sesko AD Bandung memiliki pengaruh.

\section{Uji Significant F}

\section{Tabel.10 Uji Significant F}

\begin{tabular}{|c|c|c|c|c|c|c|}
\hline \multicolumn{7}{|c|}{ ANOVA $^{a}$} \\
\hline \multicolumn{2}{|c|}{ Model } & $\begin{array}{l}\text { Sum of } \\
\text { Squares }\end{array}$ & df & $\begin{array}{l}\text { Mean } \\
\text { Square }\end{array}$ & F & Sig. \\
\hline \multirow[t]{3}{*}{1} & Regression & 248.630 & 1 & 248.630 & 26.336 & $<.001^{\mathrm{b}}$ \\
\hline & Residual & 311.542 & 33 & 9.441 & & \\
\hline & Total & 560.171 & 34 & & & \\
\hline
\end{tabular}

a. Dependent Variable: KESEJAHTERAAN

b. Predictors: (Constant), PENDAPATAN

Uji f merupakan uji simultan terhadap koefisien regresi. Penelitian ini dilaksanakan bertujuan untuk memahami semua pengaruh variabel bebas yang dimasukkan dalam model terhadap variabel terikat secara bersama-sama ( dalam waktu yang bersamaan).

Dari table diatas bahwa telah dipeoleh nilai f table untuk $\mathrm{n}=33$ adalah 4,14 dan $\mathrm{f}$ hitungnya 26,336 atau 26,336>4,14 dan tingkat kekeliruannya 5\% $(\alpha=0,05)$ disimpulkan menerima Ha dan menolak Ho. 


\section{KESIMPULAN dan SARAN}

\subsection{Kesimpulan}

1). Gambaran pendapatan di koperasi Viyata Virajati Seskoad Bandung sudah cukup bagus. Sesuai dengan hasil kuisioner yang telah disebarkan. Dari 15 pertanyaan yang diajukan kepada koresponden bahwa pendapatan yang diperoleh dari koperasi tersebut bisa dinikmati langsung. kemudian hasil penelitian yang telah dilaksanakan menunjukkan jika barang dagangan yang dijual di Koperasi Viyata Virajati Sesko AD Bandung sudah memenuhi kriteria penjualan yaitu menjual makanan kemasan dan perlengkapan atribut TNI AD dan mendapatkan pilihan yang paling banyak yaitu rata-rata 4,514.

2). Kesejahteraan anggota koperasi Viyata Virajati Sesko AD Bandung sudah cukup baik. Ini dapat terlihat dari antusiasnya anggota koperasi untuk membeli barang di toko Koperasi Viyata Virajati Sesko AD Bandung karena harganya terjangkau dan semuanya tertata dengan baik dan bersih. Dimana antusias anggota koperasi untuk berbelanja mendapatkan pilihan yang paling banyak yaitu rata-rata 4,6.

3). Pendapatan koperasi memiliki dampak yang signifikan terhadap kesejahteraan, dari penelitian yang telah dilakukan terlihat hasil koefisien korelasinya adalah 0,666 (66,6\%) dan memiliki arti yang kuat. Sementara hasil koefisien determinasinya adalah 44,4\%. Artinya pendapatan mempunyai pengaruh sebesar $44,4 \%$ terhadap kesejahteraan. Dan untuk sisanya sebesar 55,6\% dipengaruhi oleh faktor luar yang tidak diteliti dalam penelitian ini. Persamaan regresi linier sederhana $\mathrm{Y}=\mathrm{a}+\mathrm{bX}=8,055+1,190 \mathrm{X}$, yang berarti untuk setiap kenaikan 1 nilai pendapatan maka kesejahteraan akan meningkat sebesar 1,190. Hasil uji t telah diperoleh 5,132>1,692 (t hitung>t tabel) maksudnya Ha diterima dan Ho ditolak artinya memberikan hasil bahwa memiliki pengaruh antara pendapatan terhadap kesejahteraan di koperasi Viyata Virajati Sesko AD Bandung.

4). Permasalahan yang terjadi pada koperasi simpan pinjam Viyata Virajati Sesko AD adalah aturan untuk semua anggota koperasi yang mana wajib membayar uang simpanan sebesar Rp.200.000/bulan. Simpanan wajib ini tidak boleh diambil sampai kapanpun kecuali jika anggota koperasi tersebut keluar sebagai anggota koperasi. Sementara ada sebagian anggota koperasi yang menginginkan simpanan wajib bisa diambil kapanpun jika ada anggota yang membutuhkan.

5). Upaya untuk menyelesaikan masalah tersebut adalah anggota koperasi menabung tidak hanya di koperasi saja, tetapi bisa juga mengikuti polis asuransi yang untungnya lumayan besar atau mendepositkan uang di bank yang bisa dicairkan minimal setahun sekali.

\subsection{Saran}

1). Bagi pengelola koperasi agar ditambah lagi fasilitas dan pelayanan contohnya tranksasi pembayaran dapat dilakukan dengan debet ATM. banyak anggota yang transaksi di koperasi.

2). Pengelola koperasi agar dapat memperbaiki perencanaan, pengelolaan keuangan, manajemen dan sistem administrasi sehingga akan dapat mendorong kegiatan transaksi yang lebih banyak dan minat untuk bergabung untuk menjadi anggota di koperasi Viyata Virajati Seskoad Bandung.

3). Anggota koperasi dihimbau untuk lebih meningkatkan pertisipasinya lagi pada transaksi dan ikut andil dalam segala hal agar koperasi berkembang lebih besar. 


\section{REFERENSI}

Badrudin (2021). BAB II TINJAUAN PUSTAKA. kehidupan dan penghidupan masyarakat baik materil maupun spiritual yang. Https://Docplayer.Info/.

https://docplayer.info/46236356-Bab-ii-tinjauan-pustaka-kehidupan-dan-penghidupanmasyarakat-baik-materil-maupun-spiritual-yang.html

Chaniago (2021). Pengertian Koperasi Menurut UU dan Para Ahli, Ketahui Prinsip Beserta Fungsinya. Https://Www.Merdeka.Com/.

https://www.merdeka.com/trending/pengertian-koperasi-menurut-uu-dan-para-ahliketahui-prinsip-beserta-fungsinya-kln.html?page $=1$

Diener \& Lucas (2021). Kajian Meta-Analisis Hubungan antara Self Esteem dan

Kesejahteraan Psikologis. Https://Docplayer.Info/. https://docplayer.info/63505396-

Kajian-meta-analisis-hubungan-antara-self-esteem-dan-kesejahteraan-psikologis.html

Dwi Martani dkk (2016:204). KUMPULAN PENGERTIAN MENURUT PARA AHLI.

Https://Www.Kumpulanpengertian.Com/.

https://www.kumpulanpengertian.com/2020/03/pengertian-pendapatan-menurut-paraahli.html

Kieso, W. dan W (2018), pengertian pendapatan. Https://Www.Hestanto.Web.Id/.

https://www.hestanto.web.id/pengertian-pendapatan/

Rudianto. (2015). Rudianto. 2015. Akuntansi Koperasi Edisi ke Dua. Jakarta: Erlangga. 615.

Samuelson dan Nordhaus (2018). pengertian pendapatan.

Https://Www.Hestanto.Web.Id/Pengertian-Pendapatan/.

Sugiyono (2015). Definisi Operasional : Tujuan, Manfaat dan Cara Membuat.

Https://Penerbitbukudeepublish.Com/. https://penerbitbukudeepublish.com/definisioperasional/

Sugiyono (2015). Pengertian Populasi \& Sampel Menurut Sugiyono.

Https://Www.Asikbelajar.Com/. https://www.asikbelajar.com/pengertian-populasi-

sampel-menurut-sugiyono/

Sugiyono (2016: 225). (n.d.). DATA SEKUNDER. Https://Raharja.Ac.Id/. Retrieved June 29, 2021, from https://raharja.ac.id/2020/11/08/data-sekunder/

Sugiyono (2018). Pengertian Metode Penelitian dan Jenis-jenis Metode Penelitian.

Https://Ranahresearch.Com/. https://ranahresearch.com/metode-penelitian-dan-jenismetode-penelitian/

Sugiyono (2018). Regresi Linier Sederhana. Https://Amanahtp.Wordpress.Com/.

https://amanahtp.wordpress.com/2018/04/05/regresi-linier-sederhana/ 